\title{
Os paradigmas do desenvolvimento e a desigualdade de gênero: análise das políticas públicas destinadas às mulheres no Brasil
}

\section{The paradigms of development and gender inequality: analysis of public policies for women in Brazil}

\author{
Welberte Ferreira de Araujo \\ Maria Fernanda Soares Fonseca \\ Gilmar Ribeiro dos Santos
}

\section{Resumo}

Este estudo propóe-se analisar as perspectivas conceituais que subsidiaram as políticas públicas destinadas às mulheres no Brasil e as formas de resistência ao mito global e local de bem-estar, de redução das desigualdades. Especificamente, busca apresentar as tensóes que atravessam as dinâmicas de desenvolvimento e que foram variando ao longo do tempo em âmbito nacional, influenciadas pelas coalizóes e dinâmicas internacionais. A metodologia de abordagem é exploratória e bibliográfica. A seleção e análise dos conceitos de políticas públicas, gênero e desenvolvimento propiciaram compreender os desafios das políticas públicas destinadas às mulheres em torno das perspectivas dos paradigmas do desenvolvimento. Os resultados apontam para a necessidade de um novo paradigma epistemológico de desenvolvimento que busque romper com as referências naturalizadas e que considere a importância da inclusão das questôes de gênero na pauta desses novos modelos.

\section{Palavras-chave}

Desenvolvimento; Equidade de Gênero; Políticas Públicas.

\section{Abstract}

This study analyzes the conceptual perspectives that subsidized the public policies aimed at women in Brazil and the forms of resistance to the global and local myth of well-being, to reduce the inequalities that would be ensured in industrialized societies. Specifically, it presents the tensions that cross the development dynamics at the national level and that have varied over time, influenced by international coalitions and dynamics. The methodology used is exploratory and bibliographical. The selection and analysis of the concepts of public policies, gender and development provided an understanding of the challenges of public policies aimed at women around the perspectives of development paradigms. The results point to the need for a new epistemological paradigm of development that seeks to break with the naturalized references, and to consider, in turn, the importance of including gender issues in the agenda of these new models.

\section{Keywords}

Development; Gender Equity; Public Policies. 


\section{Introdução}

O termo desenvolvimento tem sido o mantra discursivo para os mais variados ramos ideológicos e políticos, ganhando novos contornos, sobretudo a partir dos anos 1950, nos países ocidentais. Seu caráter polissêmico reflete a complexidade da discussão que envolve também a busca de uma medida comum que mensure ou avalie seu resultado, não se limitando ao aspecto econômico, e que ao longo do século $\mathrm{XX}$ conduziu a dois equívocos principais.

O primeiro deles reside no fato de que os governos, estruturados na lógica de mercados e no marketing ideológico, difundiram o desenvolvimento como uma condição sine qua non para melhora da vida das populações em escala global. De acordo com Santos (2000), esse discurso representa a lógica da globalização perversa que se assenta sobre dois pilares: a tirania do dinheiro e a tirania da informação. Tal lógica quase sempre traz a ilusão de soluções técnicas como as únicas possíveis para resolver os problemas que pretende aniquilar.

O segundo equívoco é a tentativa de equiparar desenvolvimento e crescimento econômico.

Segundo Cohn (2016), os Estados na era global entendem o desenvolvimento como crescimento econômico, desconsiderando o fato de que se tratam de processos distintos. Crescimento traz a lógica de materialização, transformar as pessoas em objetos. Deste modo, a meta deste modelo imposto não é, definitivamente, o bemestar do maior número de pessoas possível, e sim o aumento da produção em larga escala, a adequação a um padrão de produção e consumo.

As críticas supracitadas se justificam na medida em que se observa que, a partir da segunda metade do século $\mathrm{XX}$, com o grande crescimento industrial impulsionado pelo avanço tecnológico dos países centrais, a concepção de desenvolvimento passou a ser amplamente difundida, sem, contudo, abarcar as reais necessidades das populações mais pobres em escala planetária.

Ademais, foi possível identificar em diferentes políticas a falsa tendência do processo de modernização crescente, que favoreceria as condiçôes de igualdade entre sexos. $\mathrm{Na}$ realidade, o que se percebeu foi um processo inverso, no qual as políticas de desenvolvimento em que a inserção das tecnologias, sobretudo aquelas mais sofisticadas, excluíam a mão de obra feminina, deixavam as mulheres à margem do desenvolvimento econômico e ratificavam os lugares sociais nos quais elas viviam como lugares naturais (PARPAT, 2010). 
134 | Welberte Ferreira de Araujo, Maria Fernanda Soares Fonseca e Gilmar Ribeiro dos Santos

Nesta perspectiva, ao se observar algumas políticas estatais sob o enfoque de gênero, surgem algumas inquietaçóes que merecem ser investigadas: quais são as estratégias de desenvolvimento adotadas pelos governos e de que maneira tais políticas públicas estão sustentadas por uma ordem conservadora de gestão? É o desenvolvimento do quê, para quem? Com quais intenções a ação estatal interfere nos papéis socialmente atribuídos a mulheres e homens? Quais as alternativas para um modelo de desenvolvimento não excludente?

Neste sentido, o objetivo do estudo foi analisar as perspectivas conceituais que subsidiaram as políticas públicas destinadas às mulheres no Brasil a partir de $1950 \mathrm{e}$ as formas de resistência ao mito global e local de bem-estar, de redução das desigualdades sociais e de gênero, pautadas no paradigma da modernização'.

O pressuposto norteador aqui delineado adota a temática de gênero ponderando as relações desiguais socialmente construídas entre homens e mulheres, vislumbradas nas políticas de desenvolvimento dos governos em diferentes contextos históricos no Brasil.

\section{Os enfoques do desenvolvimento e os seus impactos nas políticas públicas na América Latina}

O termo desenvolvimento tem sido o mantra discursivo para os mais variados ramos ideológicos e políticos, ganhando novos contornos, sobretudo a partir dos anos 1950. No entanto, seu caráter polissêmico tem evidenciado algumas dicotomias complexas em suas dimensões teóricas/analíticas, desprovidas de consenso nas suas diversas formas. Algumas correntes teóricas sinalizam que o desenvolvimento, enquanto teoria política e econômica, tem marco no pós-Segunda Guerra Mundial (1939-1945) e se consolida durante o período da Guerra Fria (1945-1989). Precisamente, a sua origem estaria condicionada ao discurso do presidente norteamericano Harry Truman, no ano de 1949, nos Estados Unidos, no qual propunha uma política de desenvolvimento que deveria chegar às regiôes mais pobres do planeta com aval norte-americano.

Apesar de tais marcos teóricos, é preciso também considerar a historicidade do termo desenvolvimento, ou seja, nas décadas de 1950 a 1970, com a teoria da modernização, estruturalismo cepalino e análise da dependência; na década de 1980, com a perspectiva centrada no Estado ou neoliberalismo; e, pós-1980, com o pós-

\footnotetext{
${ }^{1}$ O enfoque da modernização surge nas décadas de 1950 e 1960, é derivado da economia clássica e da sociologia funcionalista, cuja tese central é a de que a desigual distribuição da riqueza no mundo pode ser explicada em função dos distintos níveis de desenvolvimento tecnológico entre os países.
} 
estruturalismo ou teoria crítica pós-desenvolvimentista arregimentada pela transnacionalização do capital e nova estrutura financeira internacional (BERTONCELO, 2011).

A teoria da modernização tem seus pressupostos ancorados na economia clássica $^{2}$, na defesa de que os desníveis do desenvolvimento técnico-científico entre as nações explicariam a desigual distribuição da riqueza no mundo. Nesta perspectiva positivista evolucionista, as economias tradicionais deveriam alinhar-se aos setores capitalistas modernos ocidentais, tendo em vista que a condição sine qua non para o desenvolvimento econômico decorre dos intensos processos de industrializaçáo e urbanização. A tese era que a liberalização da mão de obra dos setores agrícolas tradicionais para setores industriais e de serviço nos centros urbanos proporcionaria a intensificação da divisão do trabalho, gerando cada vez mais crescimento econômico e, consequentemente, desenvolvimento (WOOD, 1992).

Ademais, os defensores do paradigma da modernização sublinharam a necessidade de imposição dos padrões culturais europeus (arte, política, cultura e economia) ocidentais aos países pobres (subdesenvolvidos) sob a prerrogativa de que tal medida seria o suficiente para agregar prosperidade e civilidade para tais nações. Nesta visão, o desenvolvimento implicava a modernização das condições econômicas, sociais, institucionais, ideológicas do país, ou seja, "[...] gerar as condições de possibilidade dos padrôes vigentes nos países capitalistas centrais” (GAITÁN, 2001, p. 58).

Vários dos postulados e premissas da teoria da modernização foram alvo de críticas, principalmente decorrentes do fato de atrelarem o modelo de desenvolvimento numa única via: o do evolucionismo funcionalista das sociedades europeias e norte-americana. Pontua-se ainda a insuficiência epistemológica de considerar a latente oposição entre o "tradicional" e o "moderno" como elemento central do desenvolvimento. De acordo com Bertoncelo (2011, p. 98), o equívoco reside no fato de que:

\footnotetext{
${ }^{2}$ A formulação da teoria de desenvolvimento como crescimento econômico está fortemente ligada ao trabalho de Adam Smith (1983, originalmente publicado em 1776) que, em seu livro A Riqueza das Naçôes, faz uma abordagem de como atingir o progresso econômico. Esse estudo teve influência na teoria que viria a formar o conceito de desenvolvimento econômico, obra esta que passou a ser conhecida como "Progresso e Desenvolvimento". Esse preceito impôs-se no meio acadêmico como a teoria de desenvolvimento econômico.
} 
Embora as sociedades possam ser diferenciadas em termos das características de suas estruturas sociais, não é isso que está no cerne do problema. Ao invés, para ambas as perspectivas, o desenvolvimento é moldado historicamente pela forma de vinculação das sociedades nacionais ao sistema econômico mundial, hierarquicamente organizado. E tais formas de vinculação moldam a estrutura social interna (assim como esta condiciona as formas de vinculação à economia internacional). Mais fundamentalmente, as diferentes "experiências de desenvolvimento" são entendidas como conformadas por um mesmo processo histórico, de expansão do sistema capitalista em plano global, que produziu, simultaneamente, o desenvolvimento e o subdesenvolvimento, categoria esta que substitui a noção de atraso, por sublinhar que permanecer na periferia do sistema capitalista é uma condição estrutural, historicamente moldada, e não uma mera etapa.

As críticas à teoria da modernização foram sintetizadas, principalmente entre os anos 1960 e 1970, na corrente estruturalista (tese cepalina e teóricos da dependência), que impôs uma resistência ao mito etnocêntrico da teoria da modernização, de que os países pobres deveriam seguir a trajetória dos países ricos caso almejassem o desenvolvimento (GAITÁN, 2001).

A corrente estruturalista sustentava-se no conceito de "subdesenvolvimento", entendido como uma formação histórica singular que opunha um setor "atrasado" a um setor "moderno", uma forma específica da passagem das economias préindustriais para formas mais avançadas, na lógica capitalista. Intrínsecos à tese sobre a singularidade do subdesenvolvimento latino-americano, desdobraram-se os argumentos sobre a persistência de uma "cultura da pobreza", que sustentava freios para o desenvolvimento (IVO, 2012).

Neste sentido, os meios capazes para a cisão do tal "ciclo vicioso" estariam ancorados num tripé: atração de investimentos estrangeiros, empréstimos no exterior e assistência técnica dos organismos internacionais. A hipótese era a de que, uma vez estabelecido o polo moderno, seus efeitos positivos se expandiriam, e a produção, o consumo e os valores se modernizariam (BERTONCELO, 2011).

Nesse sentido, a desigualdade seria fruto do imperialismo que transforma as estruturas econômicas e sociais existentes em estruturas solapadas (subdesenvolvidas) pelo fato de entrar em contato com o sistema econômico capitalista. Assim, conforme ressaltam Pereira e Rambla (2010), o próprio subdesenvolvimento não é consequência do isolamento das sociedades com respeito à expansão do capitalismo, mas o resultado de sua incorporação. Deste modo, as desigualdades no mundo estão 
diretamente relacionadas às pautas históricas de exploração dos países pobres pelos países ricos.

A alternativa dos países periféricos com fins ao desenvolvimento só seria possível mediante uma heterodoxia estatal centralizadora, no intuito de promover as mudanças profundas na forma de vinculação das economias desses países ao sistema capitalista mundial via industrialização, visando a uma espécie de desenvolvimento autossustentado.

A teoria da dependência aponta um novo paradigma de interpretação para o desenvolvimento, à época, articulando variáveis econômicas às políticas, ou seja, as estruturas de dominação de classes, os conflitos de interesses e as instituições sociopolíticas (IVO, 2012).

$\mathrm{Na}$ concepção de Gaitán (2001), a progressão histórica do conceito do desenvolvimento se instala no século XX, num momento de expansão do capitalismo monopolista e sob a hegemonia intelectual da teoria da modernização. Ou seja, o progresso era entendido como um processo linear encadeado em etapas para garantir a passagem do tradicional ao moderno.

No caso brasileiro, o desenvolvimento implicava a modernização das condiçôes econômicas, sociais, institucionais, ideológicas do país, ou seja, gerar as condiçôes de adoção dos mesmos padrões vigentes nos países capitalistas centrais para se alcançar os mesmos resultados (GAITÁN, 2001).

No período de 1960-1980, insurgiu o paradigma hegemônico por parte de governos e alguns economistas de considerar como sinônimos os termos desenvolvimento econômico e desenvolvimento social. Tal paradigma pautava-se na crença irrestrita de que o crescimento econômico acelerado seria suficiente para agregar melhores condições sociais para a população menos assistida.

Deste modo, o bem-estar local estaria atrelado diretamente ao desenvolvimento econômico de uma nação. Porém, uma década depois, com a ascensão do império neoliberal, ficou evidenciado que tal perspectiva náo passou de um grande equívoco.

Com base nesse argumento, não têm sido poucas as perguntas em torno do que vem a ser desigualdade social. Algumas buscam esclarecer o conceito de desigualdade, os critérios de sua identificação e mensuração e, sobretudo, as estratégias para a sua eliminação. 


\section{Politicas públicas para mulheres e a desigualdade de gênero no Brasil}

As políticas públicas ${ }^{3}$ abarcam uma multiplicidade de ações nos setores econômico, social, cultural, ambiental etc., bem como uma variedade de instrumentos e normas que as concebem e as estruturam, promovendo a regulação das açôes de governantes ou gestores públicos. Na concepção de Souza (2006, p. 25) pode-se resumir políticas públicas como:

O campo do conhecimento que busca, ao mesmo tempo, "colocar o governo em ação" e/ou analisar essa ação (variável independente) e, quando necessário, propor mudanças no rumo ou curso dessas açóes (variável dependente). A formulação de políticas públicas constitui-se no estágio em que os governos democráticos traduzem seus propósitos e plataformas eleitorais em programas e açóes que produzirão resultados ou mudanças no mundo real.

Deste modo, o viés aqui adotado é que as políticas públicas são de competência do Estado e, portanto, estabelecidas pelo direito coletivo, o que implica considerar que a qualidade do espaço da esfera pública é imprescindível para que se possa estabelecer espaços democráticos oportunos para a elaboração e execução de políticas públicas.

Nesse sentido, Parpat (2010) pondera que a história das mulheres e sua relação com o desenvolvimento são intrínsecas ao histórico das intervenções políticas nos países em desenvolvimento e à própria história do movimento de mulheres em escala global. Nesse quadro, percebe-se uma mobilização do próprio movimento feminista em prol de mudanças de paradigma acerca desse modelo de modernização que as incluía com um caráter eminentemente naturalizante, condição que contrariava teorias mais recentes sobre o tema.

Ao refletir acerca das políticas públicas para mulheres, é possível verificar ainda que, após a década de 1950, se identifica uma correlação entre a concepção de

\footnotetext{
3 Theodore Lowi (1972) desenvolveu uma das mais conhecidas tipologias sobre política pública, elaborada através de uma máxima: a política pública faz a política. Para Lowi, a política pública pode assumir quatro formatos. O primeiro é o das políticas distributivas; o segundo é o das políticas regulatórias; o terceiro é o das políticas redistributivas e o quarto é o das políticas constitutivas.
} 
desenvolvimento, numa óptica econômica, com um viés social e jurídico, que propiciou subsídios legítimos dos direitos e garantias fundamentais, que até então não eram concebidos como prioritários.

Nesse sentido, considerando as novas perspectivas do desenvolvimento, é consenso afirmar que o progresso no desenvolvimento transcende a acumulação de riqueza, vislumbrando outras dimensóes, tais como liberdade, empoderamento, cidadania, direitos humanos, bem-estar, participação e acesso a oportunidades e equidade de gênero. Parpat (2010) menciona que o movimento de mulheres dos países desenvolvidos se mobilizou em prol de mudanças de paradigma acerca desse modelo de modernização que as incluía, com um caráter eminentemente naturalizante, condição que contrariava teorias mais recentes sobre o tema, cuja análise já não mais era feita sob a óptica puramente biológica e/ou econômica.

Foi assim que esse movimento de luta pelos direitos feministas, juntamente com organismos nacionais e internacionais responsáveis, passou a incluir as mulheres nas agendas de interesses das políticas empresariais, com o argumento de que a inserção delas no processo de modernização melhoraria a eficiência dos processos de produção e contribuiria inevitavelmente para o crescimento econômico e, portanto, para o desenvolvimento.

No entanto, mesmo diante de novas perspectivas críticas ao paradigma da modernização, aponta-se que as políticas de desenvolvimento na América Latina entre 1950 e 1970 ainda privilegiaram o polo masculino e reforçaram a divisão sexual do trabalho, ao contrapor os espaços rurais e domésticos, destinados às mulheres, e os espaços urbanos industrializados, destinados aos homens (HERNÁNDEZ, 1999).

Nesse período, a política de bem-estar, aplicada pelos programas de desenvolvimento, identificava pejorativamente a mulher no seu rol reprodutivo (o cuidado, bem-estar da família e dos filhos; papel de esposa/mãe) e a convertia numa mera beneficiária passiva dos programas assistenciais, na condição de submissão e fragilidade, considerando tais açóes como condiçóes essenciais para o desenvolvimento econômico da coletividade (PEREIRA e RAMBLA, 2010; PAPART, 2010; FAO, 1996).

Moser (1993) pondera que as políticas públicas para as mulheres nos anos 1950 a 1960, tendo como concepção a abordagem do "bem-estar", correlacionavam suas diretrizes com o papel atribuído às mulheres na dimensão social. Assim, elas eram coadjuvantes nos processos e receptoras passivas nas políticas de 
desenvolvimento. As políticas emergenciais da Superintendência de Desenvolvimento do Nordeste (SUDENE) nos anos 1960 são um exemplo desse paradigma.

A SUDENE foi criada com foco no planejamento regional e embasada na industrialização, tendo como objetivo principal encontrar solução para a questão da desigualdade regional. Para além da questão do desenvolvimento regional, cabia também ao órgão a elaboração de planos de emergência em períodos de seca, repassando recursos do tesouro nacional destinados aos trabalhos assistenciais, coordenando e fiscalizando as ações desenvolvidas. É do que trata o plano diretor estabelecido na Lei 4.239, de 27 de junho de $1963^{4}$.

O Capítulo IV, artigo 26 da referida lei, faz menção ao Fundo de Emergência e Abastecimento do Nordeste (FEANE), o qual, de uma maneira geral, prevê o repasse de recursos da União com a finalidade de

Fornecimento gratuito de gêneros e objetos de uso pessoal de primeira necessidade, nas obras e serviços de emergência às pessoas inválidas, inclusive viúvas, mulheres sem arrimo e velhos de idade superior a 60 (sessenta) anos, mediante prévio alistamento para efeito de controle e fiscalização dos serviços (BRASIL, 1963, grifos nossos).

Aqui reside um ponto fundamental para o que propomos discutir. Considerando os critérios acima, destacamos a seguir alguns equívocos em relação à inserção da mulher nas políticas emergenciais da SUDENE. De modo geral, isso ocorreu na condição de "pessoas inválidas" e/ou quando da ausência do representante masculino na família (viúvas, mães solteiras e mulheres abandonadas pelos maridos). Ao utilizar essas normas de seleção, a Lei 4.239/63 determina os espaços e papéis sexuais na esfera do trabalho e das políticas públicas.

Além desses critérios, os tipos de obras e serviços ${ }^{5}$ contemplados pelo FEANE demonstram o tratamento desigual dispensado à mulher. Isso porque essas obras e serviços são considerados "trabalhos masculinos", que exigem desprendimento de

4 Esta lei aprova o Plano Diretor do Desenvolvimento do Nordeste para os anos de 1963, 1964 e 1965, e dá outras providências.

${ }^{5}$ Entende-se por obras e serviços: construção, recuperação e limpeza de cisternas, tanques, barragens, açudes, barreiros e aguadas; construção e recuperação de açudes, barreiros e aguadas; construção e recuperação de prédios públicos e residências na zona rural; fabricação de telhas e tijolos a serem utilizados em obras públicas ou mutirôes; pavimentação com paralelepípedos e produção de britas e paralelepípedos. 
força física, portanto, tornam-se trabalhos inadequados para as mulheres ${ }^{6}$. Apesar disso, coube às mulheres do semiárido uma dupla jornada de trabalho, ou seja, elas trabalham inclusive naquelas atividades consideradas mais duras, podendo-se citar as relacionadas à produção no campo de gêneros, visando à sobrevivência em meio à seca e, ainda, são cuidadoras do lar.

Destaca-se que, no ano de 1975, reconhecido como o ano internacional da mulher, a Organização das Nações Unidas (ONU) atestou a importância da luta das mulheres por seus direitos, propondo reconfigurações necessárias rumo à equidade de gênero. Neste período houve uma mudança no enfoque da mulher/gênero nas políticas de desenvolvimento. As políticas públicas sinalizavam para a necessidade da autossuficiência econômica das mulheres como meio para obter autonomia e independência. Ou seja, reconheceu-se a importância do papel da mulher como geradora (secundária) de renda para a casa.

Quanto à Política de Autossuficiência econômica ou Antipobreza (19701985), passou-se a reconhecer o trabalho realizado pelas mulheres na sociedade, ainda que em uma perspectiva secundária e relacionada ao trabalho doméstico. A Política de Enfoque Instrumental ou Enfoque do Desenvolvimento das Mulheres (1970-1980 e anos seguintes) passou a admitir o trabalho da mulher na esfera pública, contudo, como caráter voluntário, o que propendia a torná-lo não remunerado e desvalorizado. Nessa perspectiva, as competências produtivas estavam associadas com papéis tradicionalmente destinados às mulheres (costurar, cozinhar, cuidar). Ademais considera-se como secundária e complementar a contribuição econômica das mulheres (FAO, 1996).

É necessário considerar, ainda, que neste período a maioria dos projetos de desenvolvimento não somente desconsiderava as mulheres como também frequentemente as prejudicava. As mulheres não eram privilegiadas nas políticas de desenvolvimento, principalmente as relativas à economia produtiva, ou seja, estavam sujeitas aos programas/projetos isolados, específicos, pontuais, de baixo impacto e produtividade, compondo um estrato marginal ao desenvolvimento (BOSERUP, 1970).

\footnotetext{
${ }^{6}$ De certo modo representa uma reprodução da concepção naturalista da mulher, conceito introduzido por Aristóteles para explicar as relaçóes entre homens e mulheres. Segundo uma de suas leis, é natural que a mulher seja inferior, com base no argumento de que ela, incorporada na figura de Eva, tenha induzido Adão ao erro, isto na história bíblica da criação do mundo citada no livro de Gênesis. Ao contrário disto, Beauvoir (1967) defende que os homens e mulheres são seres sociais e históricos.
} 
Assim, a prevalência estereotipada da mulher no planejamento e execução das políticas de desenvolvimento reforçou a divisão sexual do trabalho, sobretudo nos países periféricos (BOSERUP, 1970), confirmando a tese de que o Estado não é neutro em relação às questôes de desenvolvimento e gênero, já que as ações estatais influem no modo como as relações sociais entre homens e mulheres são construídas, produzidas e reproduzidas no interior de uma sociedade.

$\mathrm{Na}$ década de 1980, em decorrência dos movimentos sociais, surge a perspectiva da "mulher em desenvolvimento", que passou a valorizar as contribuições econômicas do trabalho das mulheres como fator produtivo incluso. Entretanto, defendia-se a mão de obra feminina como capital humano subdesenvolvido, coadjuvante nas políticas de desenvolvimento e com reais necessidades de integração e qualificação nos programas de atividades produtivas (FAO, 1996).

É preciso pontuar que a atividade doméstica não era sequer reconhecida como trabalho ${ }^{7}$, o que inevitavelmente gerava sobrecarga de responsabilidade para as mulheres: dupla e tripla jornadas. Nesse sentido, o trabalho desenvolvido no ambiente familiar, em que se pressupóe que podem ocorrer partilhas e negociaçóes, torna-se um fardo para as mulheres, que, ao desempenharem as tarefas do lar, acabam se tornando invisíveis. Assim, o trabalho doméstico, além de não se computar como trabalho, pode contribuir para a desvalorização da mão de obra feminina, interferindo inclusive nas atividades profissionais das mulheres.

Vale ressaltar que só a partir de 1990 se inicia um conjunto de mudanças nas políticas de desenvolvimento e planejamento específicos com a perspectiva de mulher e/ou gênero por iniciativa dos governos (incluindo a América do Sul). Nesse período, é possível verificar alguns programas específicos destinados a elas nas agências de desenvolvimento sustentados no princípio da defesa da integração estrutural da perspectiva de gênero com fins à união e à redistribuição econômica da igualdade de gênero. Nessa fase há uma valorização da contribuição do trabalho da mulher, mostrando a importância da qualificação desta e a busca de um status mais alto dentro do Estado, para instâncias que trabalham o tema mulher/gênero (FAO, 1996).

No cenário recente, contemplam-se mudanças consideráveis, inclusive de uma atenção dada às políticas só para mulheres e propondo a necessidade de planejamento

\footnotetext{
7 Com a aprovação da Lei Complementar n. 150, de 2015, que regulamentou a Emenda Constitucional n. 72, os empregados domésticos passaram a gozar de novos direitos, o que não implicou necessariamente o fim da precarização do trabalho neste segmento.
} 
e inclusão de gênero nessas. Embora as políticas apresentem mudanças consideráveis, sinaliza-se para a necessidade de mudanças culturais em longo prazo.

\section{Por um outro desenvolvimento: a busca pela equidade de gênero}

Após os anos 1990, o neoliberalismo descortinou algumas dicotomias evidenciadas no ideário nacional-desenvolvimentista, tais como Estado versus Mercado e Estado versus Sociedade, sendo que o eixo central de diferentes políticas destinadas às mulheres passou a ser constituído em consonância com os novos paradigmas emergentes deste período. Assim sendo, o cenário atual sinaliza para uma perspectiva menos uniforme, em que se abandonam polaridades e se veem as relaçóes do Estado como soma positiva. Essas tendências ressaltam os problemas de visóes como a do ideário neoliberal (DINIZ, 2001, p. 41).

Nesta trajetória, novas perspectivas do desenvolvimento têm refletido sobre a constatação de que mudanças estruturais no sistema econômico com o objetivo de potencializar o crescimento não atingem a todos de maneira equitativa. Prevalece uma lógica de desenvolvimento excludente. No entanto, é preciso ponderar que essas novas abordagens críticas do desenvolvimento são destituídas de consenso entre os principais teóricos do tema.

Dessas correntes, duas parecem ser mais apropriadas para a discussão da relação entre desenvolvimento e as políticas de planejamento sustentadas na perspectiva de gênero: a perspectiva da descolonização do desenvolvimento e o desenvolvimento humano ou enfoque das capacidades (MKANDAWIRE, 2011; NDLOVU-GATSHENI, 2013b; SEN, 2000).

O elemento comum dessas correntes está no fato de apresentarem uma crítica radical às dinâmicas do atual Estado, do sistema de dominação e exploração na América Latina, e defesa do desenvolvimento para além da dimensão econômica, tendo em vista que se estabelece a partir do processo de eliminação de desigualdades entre as pessoas, Estados, naçóes, focando também em aspectos subjetivos, culturais e sociais.

A mudança social proposta pelo paradigma da descolonização do desenvolvimento $^{8}$ defende a necessidade de desconstruir o discurso do

\footnotetext{
${ }^{8}$ Esta corrente propóe uma retomada da definição de desenvolvimento da Conferência de Bandung, ocorrida em 1955, que reuniu ao todo 27 naçóes, tendo como eixo central a luta contra o
} 
144 | Welberte Ferreira de Araujo, Maria Fernanda Soares Fonseca e Gilmar Ribeiro dos Santos

desenvolvimento hegemônico e tomar consciência dos vários mecanismos de poder que esse discurso encerra ao categorizar o mundo entre o mundo desenvolvido, detentor de conhecimento e dos modelos que funcionam, e o subdesenvolvido, que espera a intervenção do mundo desenvolvido (NDLOVU-GATSHENI, 2013b; MKANDAWIRE, 2011).

Nessa perspectiva, o que se propõe, desde o início, é o abandono da versão do desenvolvimento tradicional "de Truman", em que o desenvolvimento é visto como uma missão euro-americana de desenvolvimento do Sul, e a adoção dos princípios da Conferência de Bandung, que definiu desenvolvimento como a aspiração humana de se libertar da dominação política, econômica, ideológica, epistemológica e social instalada pelo colonialismo e definiu as possibilidades para reversão dos impactos do colonialismo, principalmente nos países africanos e da América Latina (MKANDAWIRE, 2011).

A centralidade deste paradigma perpassa a compreensão de que os estudos do desenvolvimento podem contribuir para desafiar a estrutura assimétrica do poder global que limita qualquer possibilidade de desenvolvimento no Sul global. Nesse sentido, a descolonização é um processo inacabado que deu lugar à colonialidade, que é uma estrutura de poder pouco aparente que equaliza as relações coloniais de dominação e exploração, decorridas décadas do fim do colonialismo; e é este processo que precisa ser revertido. Outro ponto importante é balizar as discussóes sobre desenvolvimento considerando as ideias e os projetos de movimentos emancipatórios nos países em desenvolvimento, bem como seus líderes e seus pensadores (NDLOVU-GATSHENI, 2013b).

Particularmente, considerando o histórico de desigualdade de gênero em escala planetária, o enfoque das capacidades proposto pelo economista e filósofo indiano Amartya Sen (2000) vislumbra uma possibilidade específica de analisar e julgar as reais liberdades desfrutadas pelos indivíduos, considerando o fato da existência de um vínculo evidente entre, por um lado, as desigualdades e discriminaçóes com base no gênero e, por outro lado, a pobreza e exclusão social, ou seja, as sociedades e comunidades onde persistem discriminações com base no gênero, ao nível econômico, político, social e cultural, são também sociedades e comunidades com maiores constrangimentos e entraves no seu processo de desenvolvimento global.

colonialismo, o direito de todos os povos à autodeterminação, a luta pela independência e pela liberdade de escolha dos estados relativamente aos seus próprios sistemas políticos. 
Na perspectiva do que propôs Sen (2000), é possível identificar algumas das políticas públicas para mulheres no Brasil, sobretudo no início do século XXI, que têm como princípio a análise de desenvolvimento enquanto liberdade, preservando a autonomia do sujeito, as liberdades individuais e a superação das provaçóes individuais enquanto constitutivas do verdadeiro desenvolvimento. Foi o caso da criação da Secretaria de Políticas para as Mulheres (SPM), em 2003, surgida em resposta à reivindicação dos movimentos feministas e de mulheres e aos compromissos assumidos pelo país em tratados e convençóes internacionais. Vale destacar ainda a elaboração, via governo federal, dos Planos Nacionais de Políticas para as Mulheres (PNPM), elaborados, respectivamente, em 2004, 2008 e 2013, como instrumentos de viabilização do processo de gestão das políticas para mulheres por intermédio da Secretaria de Políticas para as Mulheres (SPM), responsável pela coordenação da política'.

O elemento comum de tais políticas reside na necessidade de inserção da transversalidade de gênero ${ }^{10}$ na gestão das políticas públicas. Ademais, os planos propóem o desencadeamento de um processo amplo e complexo de participação social e atuações intersetoriais, otimizando os recursos disponíveis e garantindo sua aplicação em políticas com a finalidade de reduzir as desigualdades entre mulheres e homens. Deste modo, tais políticas representam uma contraposição às noções econômicas que avaliam o desenvolvimento, a pobreza e as oportunidades dos indivíduos meramente baseadas nas rendas ou recursos e à tentativa cínica de muitas visôes econômicas de fazer uma economia sem juízos de valor, distante da ética: uma economia "neutra" (SEN, 2000).

A igualdade de gênero significa acesso a iguais oportunidades entre mulheres e homens para fazer escolhas, para aceder aos recursos, aos direitos e ao poder, e para

\footnotetext{
9 A trajetória de consolidação dessas políticas foi, contudo, afetada pelas sucessivas mudanças sofridas por essa institucionalidade nos últimos três anos (2015-2018). Atualmente, no governo federal, a Secretaria Nacional de Políticas para as Mulheres está subordinada ao Ministério da Mulher, da Família e dos Direitos Humanos (MMFDH), de acordo com o Decreto n. 9.673, de 2 de janeiro de 2019.

${ }^{10}$ A transversalidade das políticas de gênero é, ao mesmo tempo, um construto teórico e um conjunto de açóes e de práticas políticas e governamentais. Enquanto construto teórico orientador, a transversalidade das políticas de gênero consiste em ressignificar os conceitos-chave que possibilitam um entendimento mais amplo e adequado das estruturas e dinâmicas sociais que se mobilizam — na produção de desigualdades de gênero, raciais, geracionais, de classe, entre outras (BRASIL, 2013).
} 
participar de forma plena na vida econômica, política, social e cultural das comunidades, países e regióes.

A criação das políticas públicas, sobretudo as que buscam alcançar as garantias de direitos das mulheres, precisa levar em consideração suas singularidades, suas capacidades e necessidades individuais e coletivas, com vista a criar um diagnóstico capaz de elucidar quais são as prioridades. Assim, tais políticas precisam ser elaboradas, no contexto de desenvolvimento, com a participaçáo das mulheres, num movimento "de dentro para fora".

Um dos elementos do novo paradigma do relacionamento Estado-sociedade é a revalorização do primeiro como peça fundamental do processo de desenvolvimento, e isso se contrapóe à concepção de mercado como árbitro das questôes distributivas. Por esse novo modelo, aumenta a importância da política como forma de organização da economia e da sociedade no sentido de obter bons resultados por intermédio da coordenação estatal (GAITÁN, 2001).

$\mathrm{Na}$ perspectiva de Sen (2000), é preciso ponderar que a busca pela promoção da equidade de gênero e o consequente empoderamento das mulheres contempla não somente a dimensão dos direitos humanos, mas se impóe como uma necessidade por paz, justiça social e como um valor fundamental do desenvolvimento. No entanto, tal processo instiga profundas mudanças nas relaçóes sociais e de poder, bem como alteraçóes estruturais nas práticas institucionais informais e formais através das quais as disparidades e discriminações se constituem.

Parpat (2010) assegura não ser tolerável discutir desenvolvimento sem incluir as mulheres, considerando o fato de que as relaçóes de gênero são consideradas determinantes da posição social da mulher, e não apenas como imutáveis reflexões de ordem natural, ou seja, são socialmente construídas por padrốes de comportamento. Deste modo, "[...] mulheres e desenvolvimento são um termo inclusivo, e costumam estar associados, pois denotam movimento, cujo objetivo, a longo prazo, é o alcance do bem-estar da sociedade" (PARPAT, 2010, p. 25, tradução nossa).

Por outro lado, esta perspectiva inclusiva requer igualmente um papel de protagonismo por parte das mulheres, com voz ativa na configuração dos espaços sociais em que se inserem. Vale lembrar que, em muitos lugares do mundo, o simples fato de nascer mulher já é, por si só, uma desvantagem, tornando-a vulnerável em diversos cenários de preconceito e discriminação. 


\section{Considerações Finais}

Ao adotar a perspectiva de gênero como referência para a análise, procurou-se chamar a atenção para a construção social e histórica do feminino e do masculino, e para as relaçóes sociais entre os sexos, marcadas em nossa sociedade por uma forte assimetria, em que, ao longo da elaboração dos projetos e programas, as mulheres foram alijadas das condiçôes necessárias para a equidade de gênero.

Ficou evidenciada a necessidade de interpelar as experiências de políticas públicas, de forma a questionar se seus pressupostos têm como fim o bem-estar social e a qualidade de vida das populações em iguais medidas, tendo em vista que, nas políticas públicas destinadas às mulheres, ainda é insuficiente a equidade de gênero.

Conforme demonstrado, as políticas públicas elaboradas pelos governos ao longo da segunda metade do século XX, apesar de diferentes enfoques de desenvolvimento, não foram suficientes para a superação das desigualdades entre homens e mulheres, promovendo a equidade de gênero no Brasil.

Assim, a discriminação e a desigualdade de oportunidades, além de obstarem a equidade de gênero, ainda comprometem o desenvolvimento da sociedade como um todo, em nível econômico, social e humano, dado o peso da mulher em todos esses níveis. O caminho sinaliza para a necessidade de novos paradigmas de desenvolvimento que busquem romper com as referências naturalizadas; que considerem, por sua vez, a importância da inclusão das questóes de gênero na pauta desses novos modelos; e que resultem, assim, no interesse em saber que oportunidades os indivíduos têm de acesso equitativo à educação, à saúde, à habitação, ao acesso proporcional dos recursos, enfim, de desfrutar uma vida produtiva, independentemente do sexo.

Por fim, fica evidenciado que a gênese das políticas públicas, principalmente as que procuram assegurar as garantias de direitos das mulheres, precisam levar em consideração suas especificidades, suas capacidades e necessidades individuais e coletivas, aspirando a um diagnóstico capaz de elucidar quais são as prioridades. Precisam ser construídas, no contexto de desenvolvimento, com a participação das mulheres, num movimento endógeno. Fomentá-las de forma impositiva ensejaria mais um ato de violência contra as mulheres.

Welberte Ferreira de Araujo é Doutorando do Programa de PósGraduação em Desenvolvimento Social, pela Universidade Estadual de Montes Claros (Unimontes). E-mail: welbertearaujo@gmail.com. 
Maria Fernanda Soares Fonseca é Doutoranda do Programa de Pós- Graduação em Desenvolvimento Social, pela Unimontes. Email: mfernanda_cambuy@hotmail.com.

- Gilmar Ribeiro dos Santos é Doutor em Educação: História, Política e Sociedade pela Pontificia Universidade Católica de São Paulo (PUC-SP). Professor do Programa de Pós- Graduação em Desenvolvimento Social da Unimontes. E-mail: gilrds@bol.com.br.

\section{Referências}

BEAUVOIR, Simone de. O segundo sexo. A experiência vivida. 2. ed. São Paulo: Difusão Européia do Livro, 1967. v. 2.

BERTONCELO, Edison. Revisitando os estudos de desenvolvimento. Revista Brasileira de Informação Bibliográfica em Ciências Sociais, n. 71, p. 95-122, 2011.

BOSERUP, Ester. Women's role in economic development. New York: St Martin's Press, 1970.

BRASIL. Decreto n. 9.673, de 2 de janeiro de 2019. Aprova a Estrutura Regimental e o Quadro Demonstrativo dos Cargos em Comissão e das Funções de Confiança do Ministério da Mulher, da Família e dos Direitos Humanos, remaneja cargos em comissão, Funçôes Comissionadas do Poder Executivo e Funçóes Gratificadas, transforma cargos em comissão do grupo-Direção e Assessoramento Superiores - DAS e substitui cargos em comissão do Grupo-Direção e Assessoramento Superiores - DAS por Funçôes Comissionadas do Poder Executivo - FCPE. Brasília, 2 jan. 2019. Disponível em: <http://www.planalto.gov.br/ccivil_03/_ato2019-2022/2019/Decreto/ D9673.htm>. Acesso em: 10 maio 2019.

BRASIL. Lei Complementar n. 150, de $1^{\circ}$ de junho de 2015. Dispóe sobre o contrato de trabalho doméstico; altera as Leis no 8.212, de 24 de julho de 1991, no 8.213, de 24 de julho de 1991, e no 11.196, de 21 de novembro de 2005; revoga o inciso I do art. 3o da Lei no 8.009, de 29 de março de 1990, o art. 36 da Lei no 8.213, de 24 de julho de 1991, a Lei no 5.859, de 11 de dezembro de 1972, e o inciso VII do art. 12 da Lei no 9.250, de 26 de dezembro 1995; e dá outras providências.

Diário Oficial da União, 02 jun. 2015.

BRASIL. Secretaria Especial de Políticas para as Mulheres. Plano nacional de políticas para as mulheres. Brasília, 2013. Disponível em: <https://oig.cepal.org/sites/default/files/ brasil_2013_pnpm.pdfs. Acesso em: 09 abr. 2019.

BRASIL. Lei n. 4.239, de 27 de junho de 1963. Aprova o Plano Diretor do Desenvolvimento do Nordeste para os anos de 1963, 1964 e 1965, e dá outras providências. Brasília, 27 jun. 1963. Disponível em: <http:/www.planalto.com.gov.br/ccivil_03/leis/L4239.htm>. Acesso em: 10 ago. 2018.

COHN, Gabriel. Desenvolvimento como processo civilizador. In: COHN, Gabriel. Weber, Frankfurt: teoria e pensamento social. Rio de Janeiro: Azougue Editorial, 2016. 
DINIZ, Eli. Depois do Neoliberalismo: redistribuindo a articulação Estado e desenvolvimento no novo milênio. In: BOSCHI, Renato. (Org.). Variedades de capitalismo e desenvolvimento na América Latina. Belo Horizonte: Editora da UFMG, 2001. p. 31-55.

FUNDO DAS NAÇÓES UNIDAS PARA AGRICULTURA E ALIMENTAÇÃO (FAO). Vocabulario referido a género. Guatemala, 1996. Disponível em: <http://www.fao.org>. Acesso em: 12 nov. 2018.

GAITÁN, Flávio. Desenvolvimento esquivo e as tensões do desenvolvimentismo: reflexóes sobre a América Latina na hora atual. In: BOSCHI, Renato (Org.). Variedades de Capitalismo e Desenvolvimento na América Latina. Belo Horizonte: Editora da UFMG, 2001. p. 56-85.

HERNÁNDEZ, Itiziar. Desigualdad de género em desarrollo. In: VILLOTA, Paloma. de. (Ed.). Globalización y género. Madrid: Síntesis, 1999.

IVO, Anete. O paradigma do desenvolvimento: do mito fundador ao novo desenvolvimento. Caderno CRH, v. 25, n. 65, p. 187-210, 2012.

LOWI, Theodore. Four systems of policy, politics, and choice. Public Administration Review, v. 32, n. 4, p. 298-310, 1972.

MKANDAWIRE, Thandika. 'Running while others walk': knowledge and the challenge of Africa's development. Africa Development, v. 36, n. 2, p. 1-36, 2011.

MOSER, Caroline. Gender planning and development: theory, practice and training. New York: Routledge, 1993.

NDLOVU-GATSHENI, Sabelo. Empire, global coloniality and african subjectivity. [S.l.]: Berghahn Books, 2013b.

PARPAT, Jane. Perspectives on theory and gender. In: MARCHAND, Marianne; PARPART, Jane. (Eds.). Feminism, postmodernism, development. London: Routledge, 2010.

PEREIRA, Rosângela Saldanha; RAMBLA, Francesc Xavier. Pensamento econômico feminista sobre desenvolvimento: breve viagem através do tempo. Rev. Pol. Publ., v. 14, n. 1, p. 47-54, 2010.

SANTOS, Milton. Por uma outra globalização: do pensamento único à consciência universal. 3. ed. Rio de Janeiro: Record, 2000.

SEN, Amartya. Desenvolvimento como liberdade. São Paulo: Companhia das Letras, 2000.

SMITH, Adam. A Riqueza das Naçóes: investigação sobre sua natureza e suas causas. São Paulo: Abril Cultural,1983. (Coleção Os economistas).

SOUZA, Celina. Políticas Públicas: uma revisão de literatura. Revista Sociologia, ano 8, n. 16, p. 2045, jul./dez. 2006.

WOOD, Charles. Modelos opuestos en el estudio de la migración. Alfoz, n. 91/92, p. 35-59, 1992.

Texto recebido em 15 de dezembro de 2018. Aprovado em 30 de janeiro de 2020. 